\title{
A13 THE EXTENT OF THE ANTI-CITRULLINATED PROTEIN ANTIBODY REPERTOIRE IS ASSOCIATED WITH ARTHRITIS DEVELOPMENT IN SEROPOSITIVE ARTHRALGIA PATIENTS
}

L A van de Stadt, A van der Horst, M de Koning, W H Bos, G J Wolbink, R J van de Stadt, G J M Pruijn, B A C Dijkmans, D van Schaardenburg, D Hamann Sanquin Research and Landsteiner Laboratorium, Academic Medical Center, Amsterdam, The Netherlands and the Jan van Breemen Institute, Amsterdam, The Netherlands

10.1136/ard.2010.129577m

Purpose Anti-citrullinated protein antibodies (ACPA) are probably involved in the pathogenesis of rheumatoid arthritis. During the course of disease epitope spreading might occur. In this study, the ACPA repertoire of arthralgia patients and the association with arthritis development were studied.

Methods 244 arthralgia patients positive for anti-cyclic citrullinated peptide antibodies (aCCP) and/or IgM rheumatoid factor, without clinical symptoms of arthritis were included. Arthritis was defined as the presence of one or more swollen joints at clinical examination during twice-yearly follow-up. Sera were tested at baseline for reactivity to five citrullinated peptides derived from fibrinogen (three), vimentin (one) and $\alpha$-enolase (one) and the five corresponding arginine peptides in an ELISA.

Results 65 patients (27\%) developed arthritis in a median of two joints after a median follow-up of 10 (IOR: 4-18) months. Reactivity to each peptide was significantly associated with arthritis development $(\mathrm{p}<0.01)$. The peptide reactivity pattern did not differ between patients who did or did not develop arthritis. Within aCCP positive patients, patients who recognised two or more additional citrullinated peptides developed arthritis more often $(p=0.05)$. The number of recognised peptides was positively associated with the aCCP level $(p<0.001)$. Cross-reactivity between different peptides was minimal.

Conclusion The ACPA repertoire in arthralgia patients can already be expanded. High aCCP levels are associated with a qualitatively broad ACPA response. Patients with a broader ACPA response have higher risk of developing arthritis. This indicates that epitope spreading occurs in arthralgia patients and might be initiated before onset of joint complaints. 